\title{
プロセス油中の光污染物質の化学組成と 光污染の機構
}

（昭和45年 1 月 14 日 受理）

棚 谷 篤 志 郎*

\begin{abstract}
要旨 ナフテン系のプロセス油を溶出クロマトグラム法により分割した試料につき赤外，紫外吸収スペ クトル分析を行ないその組成を検郡した。

光污染性を有する $\mathrm{A}_{2}, \mathbf{R}_{1}$ 区分はアルキル側鎖を有するアンソラセン，フエナンソレン，ナフタセン，ペ タセンなど各種多環芳香族炭化水素を含むことが知られた。このほか構造中に $\mathrm{S}, \mathrm{N}$ な゙゙が若干含まれるこ とも知られた。

光污染の機構を知るため $A_{2}, R_{1}$ 区分を光照射して活染せしめた後赤外吸収スペクトルを求めてみると， 1700 1800-cm に幅広い二CO の吸収を生じ，過酸化物，ケトン，アルデヒド，アルコール，カルボン酸 などの生成がうかがわ机る。

これとは別に $\mathrm{A}_{2}, \mathrm{R}_{1}$ 区分を窒素気流中で光照射を行なったが污染はまったく認められなかった。

これらの事実を綜合すると淡色プロセス油配合ゴムの光污染現象は，油中に存在する多環芳香族炭化水素 が酸素の存在下で光エネルギーによって起される酸化現象であるうと推測される。
\end{abstract}

\section{1. まえがき}

筆者は先にプロセス油による光污染現象は油に含まれ たある成分に基因するものであり，その外観は無色儿近 いもので，光照射を受け容易に褐色な污染物に変化する 性質を有するものであろらと推諭した ${ }^{12}$.

つぎに溶出クロマト法によりプロセス油を分割しその 性質を険討したところ大きくわけて 1) 無色, 無蛍光で 光照射に対して安定なもの，PN区分， $A_{1}$ 区分 2) 微 黄色の外観で強いけい光を有し光照射を受け容易に褐色 な污染物に変化するもの， $A_{2}$ 区分， $R_{1}$ 区分 3）光照 射に対して安定であるが始めから褐色な外観の樹脂状物 質， $\mathrm{R}_{2}$ 区分の 3 つ分けられることが知られた。 その 詳細は前報で2 報告したと㧍りである。

本報ではクロマト分割された各区分の化学組成を赤 外，紫外吸収スペクトル分析によって検討した。

また光污染区分が光照射を受けいかなる化学変化が行 なわれたかを検討した結果について報告する。

\section{2. 試}

料

試料はナフテン系油で比較的光污染性の強い油を使用 した， その物理化学的性質は表 1 の通りである.

この油を溶出クロマト法で分割した結果は表 2 は示め

†本報を〔プロセス油配合ゴムの光污染性に関する研 究 (第 3 報) と京る。

* 白石工業音研究部（画660 尼崎市元浜町 4-78)
表 1 倛試油 A D物理化学的性状

\begin{tabular}{|c|c|}
\hline 比 重 $15^{\circ} / 4^{\circ} \mathrm{C}$ & 0.9147 \\
\hline 色相ユニオン & $2-$ \\
\hline 引火点 ${ }^{\circ} \mathrm{C}$ & 162 \\
\hline 粘 度 $\operatorname{cst} 37.5^{\circ} \mathrm{C}$ & 25.48 \\
\hline$" \quad 98.9^{\circ} \mathrm{C}$ & 3.83 \\
\hline 流動点 “G & $-40^{\circ}$ 以上 \\
\hline 全酸価 $\mathrm{KOH} \mathrm{mg} / \mathrm{g}$ & 0.04 \\
\hline イオウ分 \% & 0.92 \\
\hline アニリン点 ${ }^{\circ} \mathrm{C}$ & 58.2 \\
\hline V.G.G & 0.876 \\
\hline 屈折交点 & 1.0588 \\
\hline 屈折率 $N_{D}{ }^{25}$ & 1.5188 \\
\hline 平均分子量 & 305 \\
\hline 環 $\% \mathrm{CA}$ & 26.6 \\
\hline 分 $\{\mathrm{CN}$ & 28.8 \\
\hline 析 $1 \% \mathrm{CP}$ & 44.8 \\
\hline 口/アスファルテン & 0 \\
\hline ス 窒菜ベース & 3.7 \\
\hline ᄀ\{第1アシダフィン & 14.3 \\
\hline 分第 2 アシダフィン & 32.9 \\
\hline 析 飽和分 & 49.1 \\
\hline
\end{tabular}

されるとおりで 34 フラクション，5区分あるが，その中 上り各区分の代表としてフラクション $18,22 ， 30 ， 34$ を 選び赤外，紫外吸収スペクトル分析に供した。 クロマト 分割の方法は前報2のとおりである。

\section{3. 赤外吸収スペクトル分析}

\section{1 試験方法 $^{33}$}


表 2 供試油Aの溶出クロマト分割したものの性質 微青色の外観で緑色の営光を有し，光污染性を有する油 屈折㸉 1.5188 ，イオウ分 $0.89 \%$ ，試料重量 $5.0311 \mathrm{~g}$

\begin{tabular}{|c|c|c|c|c|c|c|c|c|c|}
\hline $\begin{array}{l}\text { フラクシ } \\
\text { ョシ }\end{array}$ & 溶出㨈 & 区分 & $\underset{c c}{\underset{c c}{\text { 溶出 }}}$ & 收量 g & 小 計 & 屈折率 & 蛍 光 & 光污性 & イオウ量％ \\
\hline $\left.\begin{array}{l}4 \\
5 \\
6 \\
7 \\
8 \\
9\end{array}\right\}$ & $\begin{array}{l}\text { 石 } \\
\text { 油 } \\
\text { エ } \\
\frac{1}{\tau} \\
\text { ル }\end{array}$ & P. N & $\begin{array}{l}20 \\
" 1 \\
" 1 \\
" \\
" \\
"\end{array}$ & $\begin{array}{l}0.0266 \\
1.0699 \\
1.1212 \\
0.2499 \\
0.0458 \\
0.0120\end{array}$ & $\begin{array}{l}2.5254 \mathrm{~g} \\
50.87 \%\end{array}$ & $\begin{array}{r}- \\
1.4663 \\
1.4799 \\
1.4966 \\
- \\
-\end{array}$ & $\begin{array}{c}+シ \\
" 1 \\
" \\
" \\
" \\
" 1\end{array}$ & $\begin{array}{c}\text { ナシ } \\
" \\
" \\
" \\
" \\
"\end{array}$ & 0.19 \\
\hline $\left.\begin{array}{r}10 \\
11 \\
12 \\
13 \\
14 \\
15 \\
16 \\
17 \\
\rightarrow 18 \\
19\end{array}\right\}$ & $\begin{array}{l}\text { 四 } \\
\text { 塩 } \\
\text { 化 } \\
\text { 岩 } \\
\text { 䋜 }\end{array}$ & $A_{1}$ & $\begin{array}{l}\text { " } \\
" 1 \\
" \\
" 1 \\
" \\
" 1 \\
" 1 \\
" 1\end{array}$ & $\begin{array}{l}0.0603 \\
0.2853 \\
0.2594 \\
0.1931 \\
0.1556 \\
0.1143 \\
0.0843 \\
0.0640 \\
0.0506 \\
0.0450\end{array}$ & $\begin{array}{l}1.3119 \mathrm{~g} \\
26.43 \%\end{array}$ & $\begin{array}{r}- \\
1.5090 \\
1.5171 \\
1.5247 \\
1.5351 \\
1.5438 \\
1.5556 \\
1.5629 \\
-\end{array}$ & $\begin{array}{l}\text { " } \\
\text { " } \\
\text { " } \\
\text { " } \\
\text { " } \\
\text { " } \\
\text { " } \\
\text { " }\end{array}$ & $\begin{array}{l}\text { " } \\
\text { " } \\
\text { " } \\
\text { " } \\
\text { " } \\
\text { " } \\
\text { " }\end{array}$ & 0.57 \\
\hline $\left.\begin{array}{r}20 \\
21 \\
\rightarrow 22 \\
23 \\
24 \\
25 \\
26 \\
27 \\
28\end{array}\right\}$ & 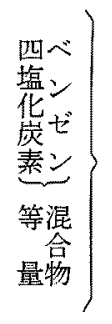 & $\mathrm{A}_{2}$ & $\begin{array}{l}" 1 \\
10 \\
" 1 \\
" 1 \\
" \\
" 1 \\
" 1 \\
" 1 \\
\prime \prime\end{array}$ & $\begin{array}{l}0.5325 \\
0.1894 \\
0.1091 \\
0.0653 \\
0.0369 \\
0.0240 \\
0.0145 \\
0.0103 \\
0.0080\end{array}$ & $\begin{array}{l}0.9909 \mathrm{~g} \\
19.96 \%\end{array}$ & $\begin{array}{r}1.5880 \\
1.6310 \\
1.6460 \\
1.6504 \\
- \\
- \\
- \\
-\end{array}$ & 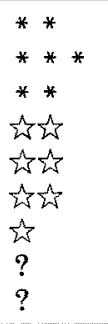 & $?$ & 3.24 \\
\hline $\left.\begin{array}{r}29 \\
-30 \\
31 \\
32\end{array}\right\}$ & $\begin{array}{l}\text { エ } \\
\text { 千市 } \\
\text { ルル }\end{array}$ & $\mathrm{R}_{1}$ & $\begin{array}{l}20 \\
\prime \prime \\
\prime \prime \\
\prime \prime\end{array}$ & $\begin{array}{r}0.0585 \\
0.0150 \\
0.0046 \\
\end{array}$ & $\begin{array}{l}0.1366 \mathrm{~g} \\
2.72 \%\end{array}$ & $\begin{array}{l}- \\
- \\
- \\
\end{array}$ & 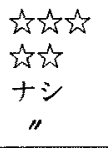 & $\begin{array}{l}90 \\
9\end{array}$ & 3.47 \\
\hline $\left.\begin{array}{r}\rightarrow 33 \\
34\end{array}\right\}$ & $\left.\begin{array}{l}\text { メタノ } \\
\text { タル }\end{array}\right\}$ & $\mathbf{R}_{2}$ & $"$ & $\begin{array}{l}0.0150 \\
0.0435\end{array}$ & & - & $"$ & $\stackrel{0}{00}$ & 1 \\
\hline
\end{tabular}

一赤外，紫外吸収スペクトル分析に供した試料

*紫色の蛍光とその程度

约緑色の蛍光とその程度

- 光污染性とその程度

○褐色の外観だが光污染性なきもの

なおすべての試験が終了後各フラクションは大区分ごとに集めJISK-2663によりイオウ量を測定した。

各区分を代表する油状の試料を $\mathrm{KBr}$ の結晶でできた 2 枚の試料板の亦いたにはさみ，赤外分光器にとりつけ その吸收を求めた。

分光器：日立 EPI-G2 型 回析格子型赤外分北光度

計試料の取扱：KBr サンドイッチ法

\section{2 測定結果の解析 ${ }^{4>5) 62}$}

各試料についての吸収の归属は表 3 に示的す。

3.2 .1 非活染区分 $\left(\boldsymbol{A}_{1}\right.$ 区分， F 18) 結果恃図 1 亿示め されると㧍りで吸収带の数は少なく，組成の比較的簡単 な炭化水素である，2800２950-cm にかけて $\mathrm{CH}_{3}, \mathrm{CH}_{2}$ の伸縮振動と $1370,1450^{-\mathrm{cm}}$ の $\mathrm{C}-\mathrm{CH}_{3}$ 変角振動が強く 認められる。つぎに抄がであるが $3050^{-\mathrm{cm}}$ に芳香㻴 の=CH- 伸縮振動， $1600^{-\mathrm{cm}}$ に芳香環面内 $-\mathrm{C}=\mathrm{C}-$ 伸縮 振動が認められる。これら芳香環に関する吸収は $\mathrm{CH}_{3}$, $\mathrm{CH}_{2}$ の吸収にくらべ相対的に弱いので, このフラクシ ヨンは鎖の大きいアルキル基を有するアルキルベンゼ ン，アルキル側鎖を有するナフテンなどであるう。

3.2 .2 光污染区分 a. $\mathbf{A}_{2}$ 区分 $(\mathbf{F} 22)$ 前の F18 に 
表 3 溶出クロマト分割物の赤外吸収の帰属

\begin{tabular}{|c|c|c|c|c|c|c|c|c|}
\hline \multirow{2}{*}{$\begin{array}{l}A_{1} \\
\text { F18 }\end{array}$} & \multicolumn{4}{|c|}{$\mathrm{A}_{2}$} & \multirow{2}{*}{\multicolumn{2}{|c|}{$\begin{array}{l}\mathbf{R}_{1} \\
\text { F30 }\end{array}$}} & \multirow{2}{*}{$\begin{array}{l}R_{2} \\
\text { F33 }\end{array}$} & \multirow[b]{2}{*}{ 帰 } \\
\hline & \multicolumn{2}{|c|}{ F20 } & \multicolumn{2}{|c|}{ F22 } & & & & \\
\hline - & - & & - & & 3400 & $\bar{w}$ & $3300 \mathrm{vs}$ & -OH の伸縮 \\
\hline 3050 wsh & 3050 & wsh & 3050 & wsh & 3050 & wsh & $3050 \mathrm{wsh}$ & 芳香環 $=\mathrm{CH}-$ - 伸縮 \\
\hline $3000 \cdot \mathrm{s}$ & 3000 & $\mathrm{~s}$ & 3000 & $\mathrm{~s}$ & - & & - & $=\mathrm{CH}-$ の伸縮 \\
\hline 2940 vs & 2950 & vs & 2950 & vs & 2950 & vs & 2950 vs & $-\mathrm{CH}_{3}$ の伸縮 \\
\hline $2920 " 1$ & 2925 & $"$ & 2925 & $\pi$ & 2925 & " & $2925 "$ & $-\mathrm{CH}_{2}-の$ 伸縮 \\
\hline $2855 "$ & 2860 & $"$ & 2860 & $" \prime$ & 2860 & " & $2860 "$ & $-\mathrm{CH}_{3},-\mathrm{CH}_{2}-\sigma$ 伸縮 \\
\hline 一 & 1920 & w & 1910 & $"$ & 一 & & - & 芳香環面外の $=\mathrm{CH}-$ 変角 \\
\hline - & - & & - & & - & & $1740 \mathrm{wsh}$ & $\mathrm{RCOOR}^{\prime} の=\mathrm{CO}$ 伸縮 \\
\hline - & - & & - & & 1728 & wsh & - & $\mathrm{RCHO} の=\mathrm{CO}$ 伸縮 \\
\hline - & 1700 & $\mathrm{w}$ & 1700 & w & 1708 & $\mathrm{~s}$ & $1708 \mathrm{~s}$ & $\mathrm{RCOOH} の=\mathrm{CO}$ 伸縮 \\
\hline- & - & & - & & - & & $1660 \mathrm{~m}$ & $\mathrm{RCHO} の=\mathrm{CO}$ 伸縮 \\
\hline $1600 \mathrm{~s}$ & 1600 & $\mathrm{~s}$ & 1600 & s & 1595 & $s$ & $1600 \mathrm{~s}$ & 芳香環面内の-C=C-伸縮 \\
\hline $1500 \mathrm{w}$ & 1490 & wsh & 1490 & wsh & - & & - & \\
\hline 1450 vs & 1450 & vs & 1450 & & 1450 & & 1450 vs & $\mathrm{C}-\mathrm{CH}_{3}$ の非対称変角 \\
\hline $\begin{array}{c}1370 \text { vs } \\
-\end{array}$ & $\begin{array}{r}1370 \\
-\end{array}$ & vs & $\begin{array}{l}1375 \\
1260\end{array}$ & $\begin{array}{l}\text { vs } \\
w\end{array}$ & $\begin{array}{l}1375 \\
1260\end{array}$ & $\begin{array}{l}\mathrm{vs} \\
\mathrm{m}\end{array}$ & $\begin{array}{l}1375 \mathrm{vs} \\
1260 \mathrm{~m}\end{array}$ & $\bigcirc-\mathrm{COOR} \omega=\mathrm{CO}$ \\
\hline - & 1180 & $\mathrm{~m}$ & 1180 & $\mathrm{~m}$ & - & & - & 芳香環 3 置換体の $\mathrm{CH}$ 面内変角 \\
\hline $1030 \mathrm{~m}$ & 1035 & $\mathrm{~m}$ & 1035 & $\mathrm{~m}$ & 1035 & w & $1015 \mathrm{~s}$ & ? \\
\hline- & 960 & w & 960 & $\mathrm{w}$ & - & & - & $\mathrm{RCH}=\mathrm{CHR}^{\prime} \odot \mathrm{CH}$ 面外変角 \\
\hline $870 \mathrm{~s}$ & 870 & $\mathbf{s}$ & 870 & $\mathrm{~s}$ & 875 & w & $875 w$ & 芳香㻴 1 置換体の $\mathrm{CH}$ 面外変角 \\
\hline 870 wsh & 850 & wsh & 850 & wsh & - & & - & ? \\
\hline - & 830 & wsh & 830 & wsh & - & & - & $?$ \\
\hline $810 \mathrm{~s}$ & 810 & $\mathrm{~s}$ & 810 & $\mathrm{~s}$ & 810 & $\mathrm{~s}$ & $815 \mathrm{~s}$ & 芳香環 2,3 置換体の $\mathrm{CH}$ 面外変角 \\
\hline $780 \mathrm{~m}$ & 780 & $\mathrm{~m}$ & 780 & $\mathrm{~m}$ & 780 & $\mathrm{~m}$ & $780 \mathrm{w}$ & ? \\
\hline $745 \mathrm{~s}$ & 750 & s & 750 & s & 750 & $\mathrm{~m}$ & $750 \mathrm{~m}$ & 芳香環置換体の CH 面外変角 \\
\hline 720 wsh & 730 & wsh & 730 & wsh & 725 & wsh & 725 wsh & $\left(-\mathrm{CH}_{2}-\right)_{\mathrm{n}} \mathrm{CH}_{3}$ の $-\mathrm{CH}_{2}-$ 変角 \\
\hline $700 \mathrm{~s}$ & 700 & $\mathrm{~s}$ & 700 & $\mathrm{~s}$ & - & & $700 \mathrm{w}$ & 芳香環 3 置換体の面外変角 \\
\hline - & 640 & $\mathrm{w}$ & 625 & w & - & & - & \\
\hline- & 580 & $\mathrm{w}$ & 580 & $\mathrm{w}$ & 580 & & - & $=$ CS $の$ 伸縮 \\
\hline - & 540 & $\mathrm{w}$ & 540 & $w$ & - & & - & \\
\hline $470 \mathrm{w}$ & 475 & $\mathrm{w}$ & 475 & w & 470 & w & $475 \mathrm{~m}$ & $?-\mathrm{S}-\mathrm{S}-$ \\
\hline
\end{tabular}

単位: 波数 $\mathrm{cm}^{-1}$

吸収の程度：vs 非常に強い, $\mathrm{s}$ 強い, $u, m$ 中程度, w弱い, sh 有の吸収

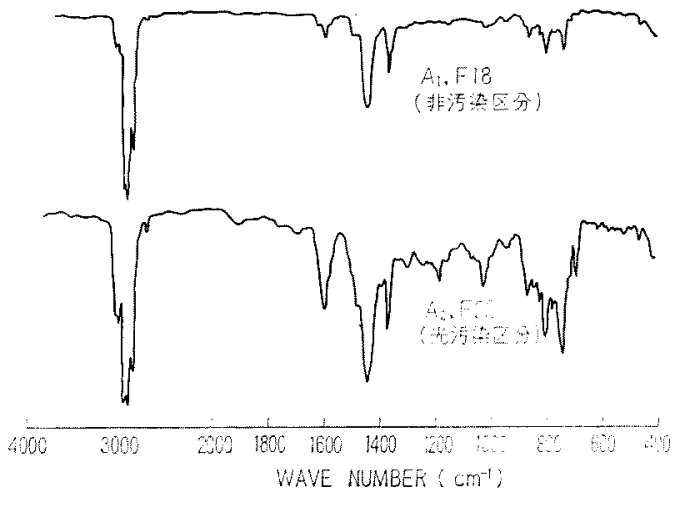

図 1 各フラクションの赤外吸収スペクトル
比較する上芳香環の存在を示す $3050,1600^{-\mathrm{cm}}$ の吸収が $\mathrm{CH}_{3}, \mathrm{CH}_{2}$ の吸収に比し相效的に大きくなっている。 つ ぎに芳香環面内 $-\mathrm{C}=\mathrm{C}$ - 伸縮振動を示す $1600^{-\mathrm{cm}}$ の吸収 は幅広くなって扰り縮合環の存在がうかがわれる，また このフラクションは屈折率1.64と高い值を示している点 からみて多環芳香族炭化水素であろう。そのほか 500 $680^{-\mathrm{em}}$ にかけて C-S と扔ぼしき吸收, $1700^{-\mathrm{cm}}$ に>CO と扔ぼしき吸収が若干認められる。

b. $\mathbf{R}_{1}$ 区分（F 30）1600-cm に幅広、吸収を持ち芳香 族縮合環の存在がうかがわ扎る。組成的にはF 22 と同し く多環芳香族炭化水素であろう。新たに 1700〜1760- $\mathrm{cm}$ に>CO の強い吸収が認められる。

3.2 .3 褐色樹脂状区分（ $\mathbf{R}_{2}$ 区分， F 34）外観は褐色 


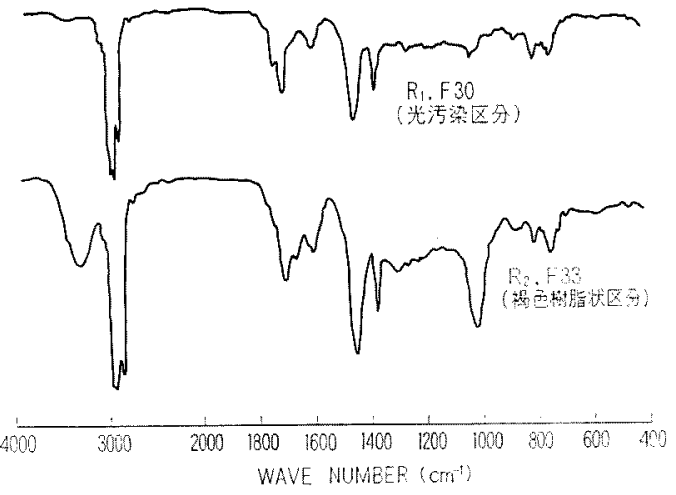

図 2 各フラクションの赤外吸収スペクトル

の樹脂状物で支る. $3330^{-\mathrm{cm}}$ に会合した OH の伸縮振 動, $1600 \sim 1740^{-\mathrm{cm}}$ に $\mathrm{CO}$ の伸縮振動, $1020^{-\mathrm{cm}}$ に $>\mathrm{CO}$ の伸縮振動と $\mathrm{OH}$ 面内変角振動などが強く認めb れる. また $3050,1600^{-\mathrm{cm}}$ に芳香環の存在を示寸吸収む 認められる、綜合するとアルキル側鎖を有する多環芳香 族炭化水素が酸化を受けケトン，アルデヒド，アルコー ル，カルボン酸などに変じたものと解される。

\section{4. 紫外吸収スペクトル分析}

\section{1 試験方法 7}

各試料はそれそれれシクロへキサンに溶解しベックマン 型分光光度計を用いて紫外部の吸收求めた。

この試験は感度が特に高く溶剂の純度が問題となるの で，試真特級のシクロヘキサンをさらにシリカゲル，ア ルミナゲルを充てんしたクロマト管を通して精製したも のを用いた。

分光機 : 島津 QR-50 形分光光度計

溶 剂: シクロヘキサン

試料濃度： $3 \mathrm{mg} / \mathrm{l}$ シタロヘキサン

\section{2 測定結果の解析 ${ }^{4) 783}$}

4.2.1 非污染区分（A, 区分，F 18） $250 \sim 300 \mathrm{~m} \mu$ に かけて微細棈造をもつ幅広く弱い吸収があるがこれはア ルキルベンゼンの吸収である。 $230 \mathrm{~m} \mu$ の吸収はアルキ ルナフタレンの吸収と思われる。

\section{2 .2 光污染区分}

a $\mathbf{A}_{2}$ 区分（F 22） $258 \mathrm{~m} \mu$ に強い吸収があるがこれ はアルキルフェナンソレン，アルキルアンソラセンなど 芳香族三環化合物の吸収である. 230，258 (幅広) $\mathrm{m} \mu$ に アルキルナフタレンの吸収が認められる。

b $\mathbf{R}_{1}$ 区分（F 30） $258 \mathrm{~m} \mu$ に最大の吸收が認められ 三堎の芳香族炭化水素の存在が知られる。溶出クロマト

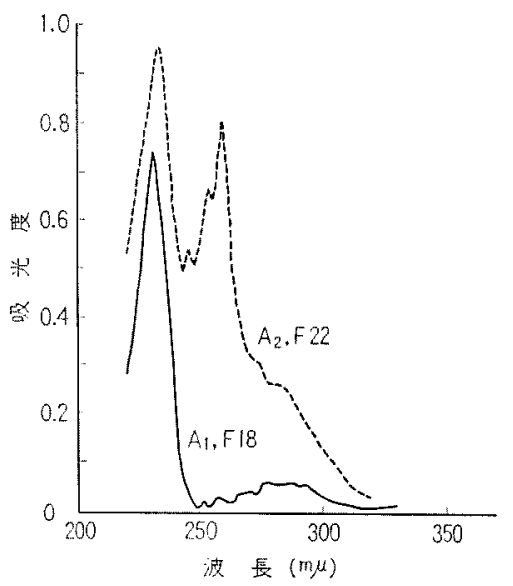

図 3 フラクション18.22 の紫外吸収スペクトル

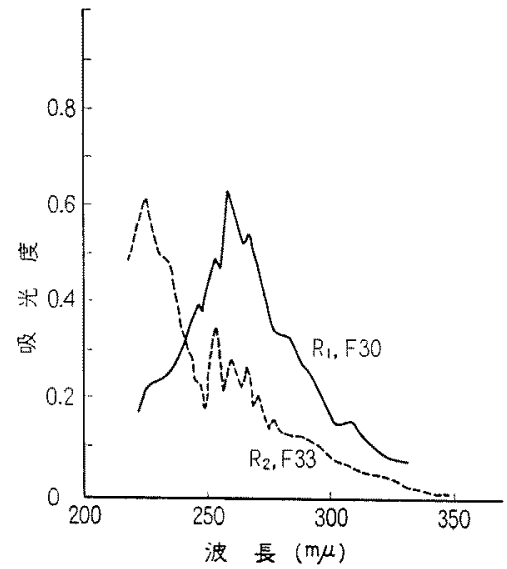

図 4 フラクション 30.33 の紫外吸収スペクトル

表 4 紫外吸収スペクトルに現われたピークの波長

\begin{tabular}{|c|c|c|c|c|c|}
\hline \multirow{2}{*}{\multicolumn{2}{|c|}{$\begin{array}{c}\mathrm{A}_{1}, \mathrm{~F}_{18} \\
-\mathrm{m} \mu) \\
-\end{array}$}} & \multirow[t]{2}{*}{$\begin{array}{c}\mathrm{A}_{2}, \mathrm{~F} 22 \\
(\mathrm{~m} \mu)\end{array}$} & \multirow{2}{*}{$\frac{\begin{array}{c}\mathrm{R}_{1}, \mathrm{~F} 30 \\
(\mathrm{~m} \mu)\end{array}}{224 \mathrm{wsh}}$} & \multicolumn{2}{|c|}{$\begin{array}{c}\mathrm{R}_{2}, \mathrm{~F} \\
(\mathrm{~m} \mu)\end{array}$} \\
\hline & & & & 224 & $\mathbf{s}$ \\
\hline 230 & vs & 232 vs & 一 & - & \\
\hline$\ldots$ & & & - & - & \\
\hline - & & $248 \mathrm{~s}$ & $246 \mathrm{~s}$ & - & \\
\hline 250 & & $254 \mathrm{~s}$ & $252 \mathrm{~s}$ & 252 & s \\
\hline 258 & & $258 \mathrm{vs}$ & 258 vs & 258 & $\mathrm{~s}$ \\
\hline 266 & vw & - & $265 \mathrm{~s}$ & 264 & $\mathbf{s}$ \\
\hline 270 & & 274 wsh & - & - & \\
\hline \multirow[t]{2}{*}{276} & & - & - & - & \\
\hline & & 280 wsh & 284 wsh & - & \\
\hline
\end{tabular}

吸収の程度：vs 非常に強い, s 強い，w弱い，sh背 の吸収 
法による溶出の順位からみてさらに環数の多いものも当 然含まれるものと想像される。このフラクションは緑色 の営光を有する点からみて $280 \mathrm{~m} \mu$ の昅収はベンズフエ ナンソレンまるいはナフタセンなど四環の芳香族炭化水 素のものであろう.

$308 \mathrm{~m} \mu$ の吸収はさらに環数の多いペンタセンのbの であるう。专た元素分析，赤外分析の結果 $>\mathrm{C}=\mathrm{S}$ の存 在がらかがわれるので $280 \mathrm{~m} \mu$ の昅収はベンゾチオフェ ンの吸収とも解することができる。

4.2.3 䙓色樹脂状区分（ $\mathbf{R}_{2}$ 区分， F 34） $224 \mathrm{~m} \mu$ の 吸収は同定困難であるが，赤外分析の結果から>COの 吸収が認められているので $208 \mathrm{~m} \mu$ のベンゾノド吸収 带が移動したものではないかと推測される。

\section{5. 各フラクションの組成同定結果 438 \%9}

溶出クロマト法によって一応の分割はなされている が, 各フラクションとも数多くのアイソマーの混合物で あり組成の確奏な同定は困難である、しかしながらク口 マト法での溶出順位, 赤外, 紫外吸収スペクトルの結果 などを綜合すると表 5 にほぼまとめられる。

今回問題点となっている光污染区分 $\left(A_{2}, R_{1}\right)$ は三環以 上の芳香環を有する炭化水素が主成分となっていること が確認できる。

\section{6. 各フラクションの光化学変化}

\section{1 各フラクションへの光照射}

溶出クロマト法により分割された試料を，別に小さな 試験管に取り分け光照射し褐色に活染せしめた後，その 組成変化を赤外吸収スペクトル分析により検討した．

促進耐候性試験機：東洋理化工業 WE-2 型

表 5 各フラクションの化学組成同定結果

\begin{tabular}{|c|c|}
\hline フラクション & 闤 \\
\hline $\mid \begin{array}{c}A_{1}, F 18 \\
\text { 非浯染区分 }\end{array}$ & $\begin{array}{c}9-R \\
(255 \sim 280)\end{array}$ \\
\hline \begin{tabular}{|c|}
$A_{z}, F 22$ \\
光清潜区产
\end{tabular} & 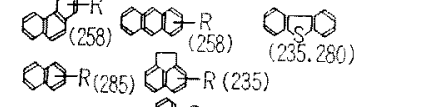 \\
\hline 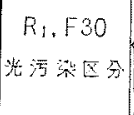 & 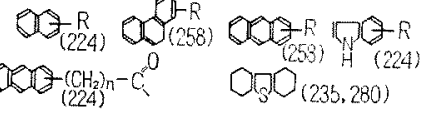 \\
\hline 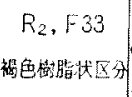 & 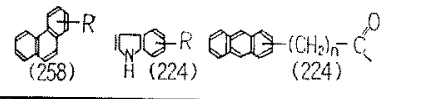 \\
\hline
\end{tabular}

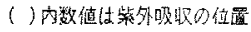

光照射時間 : 3 時間

赤外分析：試料の取扱は 3.1 に同じ

6.2 測定結果の解析 ${ }^{(0), 11), 12)}$

6.2.1 非変色区分 $\left(\mathbf{A}_{1}\right.$ 区分， F 18）光照射に上っ て $1700^{-\mathrm{cm}}$ に極くわずかの 严O の吸収が諗められる が，3 時間程度の光照射では本翼的な組成変化は起って いないとみてよいであるう(図 5 )。

6. 2.2 光活染区分 $\left(\mathbf{A}_{2} / \mathbf{F} 22, \mathbf{R}_{1} / \mathbf{F} 30\right)$ 新たに 3400 -cm に会合した $\mathrm{OH}$ の吸収が認められる.1700〜1600

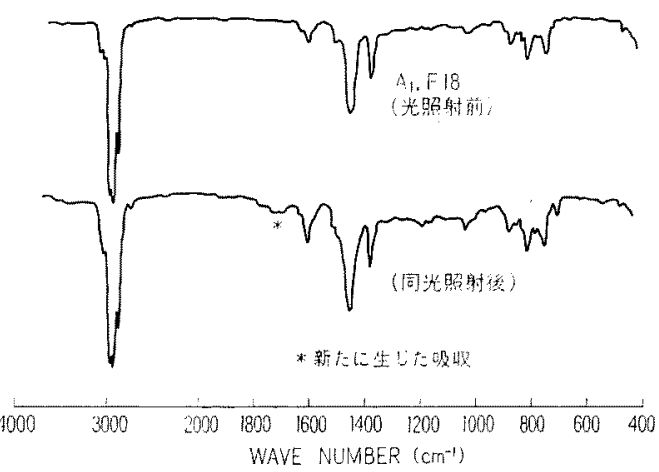

図 5 非光污染区分の赤外吸収スペクトル

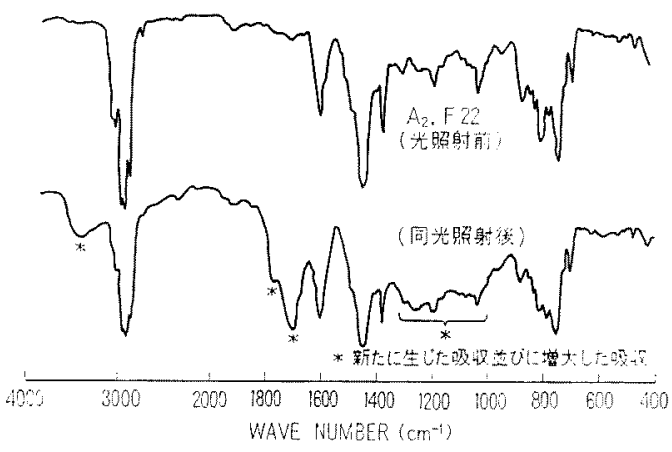

図 6 光污染区分の光照射後の赤外吸収スペクトル
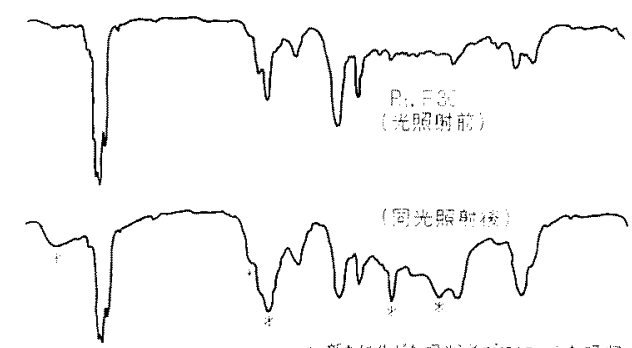

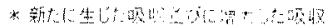

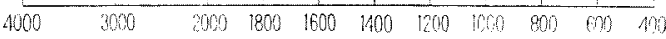

WAVE NUKOER $\left(\mathrm{NI}^{-3}\right)$

図 7 光污染区分の光照射後の赤外吸収スペタトル 
表 6 光照射後新たに生じた吸収とその帰属

\begin{tabular}{|c|c|c|c|c|}
\hline $\mathrm{A}_{2}, \mathrm{~F} 22$ & $\begin{array}{l}A_{2}, \mathbf{F} 22 \\
\text { 光沿射後 }\end{array}$ & $\mathrm{R}_{1}, \mathrm{~F} 30$ & $\begin{array}{l}R_{1}, F 30 \\
\text { 光照射後 }\end{array}$ & 骵 \\
\hline- & *3400 s & $3400 \mathrm{w}$ & *3400 s & 全合した -OH の伸縮 \\
\hline $3050 \mathrm{wsh}$ & - & 3050 wsh & 3050 wsh & \\
\hline $3000 \mathrm{~s}$ & $3000 \mathrm{ssh}$ & - & - & \\
\hline $2950 \mathrm{vs}$ & 2950 vs & $2950 \mathrm{vs}$ & $2950 \mathrm{vs}$ & \\
\hline 2925 vs & 2900 vs & $2925 \mathrm{vs}$ & 2925 vs & \\
\hline $2860 \mathrm{vs}$ & 2850 vs & 2860 vs & $2860 \mathrm{vs}$ & \\
\hline $1910 \mathrm{w}$ & $1910 \mathrm{w}$ & - & 一 & \\
\hline - & - & $1870 \mathrm{wsh}$ & 1870 wsh & \\
\hline- & - & - & * $1840 \mathrm{w}$ & $?$ \\
\hline 1770 wsh & $* 1770 \mathrm{~s}$ & - & * $1770 \mathrm{msh}$ & $\mathrm{RCOR}^{\prime} の=\mathrm{CO}$ 伸篅 \\
\hline- & $\longrightarrow$ & $1728 \mathrm{wsh}$ & $1730 \mathrm{msh}$ & $\mathrm{RCHO} の=\mathrm{CO}$ 伸繀 \\
\hline- & - & $1708 \mathrm{~s}$ & $* 1710 \mathrm{vs}$ & $\mathrm{RCOOH} \omega=\mathrm{CO}$ 仰維 \\
\hline $1700 \mathrm{w}$ & * 1700 vs & - & - & \\
\hline $1600 \mathrm{~s}$ & $1600 \mathrm{~s}$ & $1595 \mathrm{~s}$ & $1600 \mathrm{~s}$ & \\
\hline 1490 wsh & $1490 \mathrm{wsh}$ & - & - & \\
\hline $1450 \mathrm{vs}$ & $1450 \mathrm{vs}$ & $1450 \mathrm{vs}$ & $1450 \mathrm{vs}$ & \\
\hline 1375 vs & $1380 \mathrm{vs}$ & $1375 \mathrm{vs}$ & 1375 vs & \\
\hline $1300 \mathrm{w}$ & $1300 \mathrm{wsh}$ & & - & \\
\hline $1260 \mathrm{w}$ & $1260 \mathrm{w}$ & $1260 \mathrm{~m}$ & $* 1260 \mathrm{vs}$ & $\circlearrowright-\mathrm{COOR} \omega>\mathrm{CO}$ \\
\hline $1180 \mathrm{~m}$ & $1180 \mathrm{~m}$ & - & - & \\
\hline- & $一$ & - & * $1090 \mathrm{vs}$ & $\mathrm{ROH} の=\mathrm{CH}$ 伸樎 \\
\hline $1035 \mathrm{~m}$ & $1040 \mathrm{~m}$ & $1035 \mathrm{w}$ & $1035 \mathrm{~m}$ & \\
\hline $960 w$ & $960 \mathrm{w}$ & - & 一 & \\
\hline $870 \mathrm{~s}$ & $880 \mathrm{~s}$ & $875 \mathrm{w}$ & $875 w$ & \\
\hline 850 wsh & $850 \mathrm{wsh}$ & - & - & \\
\hline $810 \mathrm{~s}$ & $815 \mathrm{~s}$ & $810 \mathrm{~s}$ & - & \\
\hline $780 \mathrm{~s}$ & $790 \mathrm{~s}$ & $780 \mathrm{~m}$ & *790 s & $\mathrm{RCHO} の \mathrm{CH}$ の伸縮扔よび変角 \\
\hline $750 \mathrm{~s}$ & $750 \mathrm{vs}$ & $750 \mathrm{~m}$ & $755 \mathrm{sh}$ & \\
\hline 730 wsh & 730 wsh & 725 wsh & - & \\
\hline $700 \mathrm{~s}$ & $700 \mathrm{~s}$ & - & 700 wsh & \\
\hline $625 \mathrm{w}$ & $625 \mathrm{w}$ & - & $620 w$ & \\
\hline $580 \mathrm{w}$ & $580 \mathrm{w}$ & $580 w$ & - & \\
\hline $540 \mathrm{w}$ & $540 \mathrm{w}$ & 一 & - & \\
\hline $475 w$ & $480 w$ & $480 w$ & - & \\
\hline
\end{tabular}

*新たに生じた吸収ならびに増大した吸収 記载していない吸収は表 3 を参照のこと

-cm，1200 1000-cm にかけて強くて幅広い吸収が生じ ている。したがって過酸化物，ケトン，アルデヒド，ア ルコール，エスデル，カルボン酸など各種酸化生成物が 生じたとみなされる，なお光照射条件は非変色区分と同 しであるから，この区分は光照射によって極好て変化し やすい性質のものであると解さ礼る(园6，7)。

\section{3 室素気流中での光照射}

光污染現象は先の結果でわかるように多環㤐香族岸化 水素が光照射を受け酸化を起こし褐色な物翼に変化する 現象であることが知られた。しからば酸素の無い条件下 でははたして光活染が起こらないかどうかを梌討してみ
た.

6.3.1 試験方法と試験結果 $A_{2}$ 区分を口をしぼった 封管用試験管に分取し内部の筀気を空素ガスで置換封管 したのち6.1 と同じ方法で照射時間を延長し24時間光照 射した。

その結果外峴的な変化はまったく認められなかった。 したがって光污染現象は酸素と光エネルギーが必須の条 件であることが知られた。

\section{7. プロセス油配合ゴムの光污染と化学変化}

以上の試験はクロマト分割物についての試験であった 
表 7 光污染試験用ゴム配合

\begin{tabular}{|c|c|}
\hline SBR 1502 & 70 \\
\hline NR \# 1 & 30 \\
\hline 覀鉛華 1 号 & 5 \\
\hline ステアリン酸 & 1 \\
\hline 促進剂 DM & 1.2 \\
\hline$"$ TS & 0.2 \\
\hline 老防 \#200 & 1 \\
\hline イオウ & 2 \\
\hline DEG & 2 \\
\hline クマロン樹脂 & 3 \\
\hline チタン白 & 15 \\
\hline 白哑華 A A & 40 \\
\hline 軽カル赤玉 & 30 \\
\hline Crown clay & 40 \\
\hline トクシール Gu & 20 \\
\hline 供試油 A & 15 \\
\hline
\end{tabular}

光污染が問題となっている布靴底ゴム配合に近い ものを使用した。
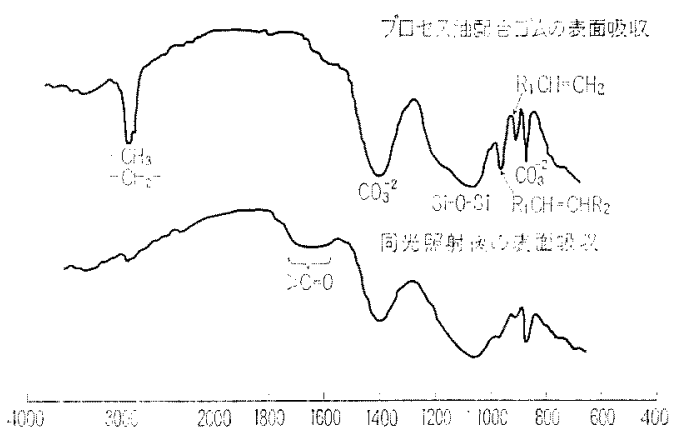

WAVE MUMEER $\left(\mathrm{cm}^{\mathrm{m}}\right)$

図 8 配合ゴムの光照射後の赤外吸収スペクトル

ので実際にゴムに油を配合した場合の変化を赤外吸収ス ペクトル分析によって追跡した.

\section{1 試験方法}

試料油：表1のとおり

ゴム配合：表 7 のおり

光照射時間：促進醀㑵試験機にて降雨を止め15時間 (第1 報の場合と同し）

赤外吸収スペクトル分析：ATR 法 ${ }^{13)}$

$2 \mathrm{~mm}$ 厚のゴム試片であるため赤外光を透過させて测 定することはできない，したがってこの試験の際はゴム 表面に全反射プリズム（KRSプリズム）密着させゴ 么表面の赤外吸収を求めた。

\section{2 測定結果}

結果は図 8 に示めされるとおりであるが，配合に使用 した充てん剤の昨収が強く出現するためゴム，油などの
吸収は明膫でない，光照射後の試料の吸収をみると 1700 〜1600-cm にかけて ンC=O の吸收が新たに生じている. この変化はゴム翼の変化かあるいは油の変化によるもの か分離して考えること估困難であるが，光照射の時間が 比較的短いので油自身の変化上みてよいであるう。

\section{8. まと め}

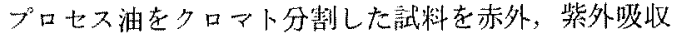
スペタトル分析により検討すると同㭙に，光污染せしめ た後の組成変化, またプロセス油配合ゴムを光污染せし めたものの組成变化などを検討したがこれらの結果を綜 合すると次のとおりである。

1) プロセス油をクロマト分㓶したもののうち，光活 染性を有方る $A_{2}, R_{1}$ 区分はアルキル側鎖を有するアン ソラセン，フェナンソレン，バンズフェナンソレン，十 フタセン，ペンタセンなど三環以上の芳澘環を有す多 環芳香族炭化水素がその主成分である。

2 ）元素分析，赤外，紫外吸収スペクトルの結果から イオウ，空秦などを含を復萃環状化台物も若干合まれる ものと考えられる。

3) $A_{2} ， R_{1}$ 区分はわずかな光照射によって褐色な污染 物翼に变化する性簤を有している，生成したこの褐色な 污染物には> $\mathrm{O}=\mathrm{C} の$ 存在が認めbれ，過酸化物，ケト ン，アルデヒド，アルコール，エステル，カルボン酸な どの存在がうかがわれる。

4) 窒素ガス気流中では光照射を行なっても泒染は生 しない。したがって光污染は酸素の存在下で起こる光化 学変化とみなされる。

5 ) 光污染区分 $A_{2}, R_{1}$ は強い蛍光を有する点から理 解されるように光エネルギーを他のエネルギーに転換さ せる性質 ${ }^{(4)}$ を有している。

光污染現象とは光污染物質に与えられた光エネルギー が蛍光エホルギーへの再転撸を起こすほか化学反応工ネ ルギーに転换し，それ自身が有する置換側鎖が酸化を受 けることによって生じる現象であるう。

6）この光污染区分の主成分であるアンソラセン，フ エナンソレンなどは染料の母体として知られて拉り，基

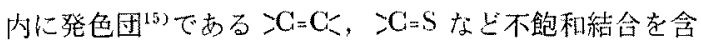
んでいる，さらに光照射孛受けて同しく発色団でるる こ $=\mathrm{O}$ が導入されると同時に組成内に含まれる若干の䇪 素化合物，光照射の結果生じ-OH，-COOH なと助色 団などが復雑にからみ合って褐色に発色し污染が起るむ のであろらと推測される。

なお次報では光污染物䱋がゴムの老化性におよばす効 
果について検討した結果を報告する。

〔附記】本研究は昭和42年 5 月18日，第34回日本ゴム 協会総会に执いて発表した。

〔謝辞】本報ならびに第 1 報, 第 2 報の要旨をまとめ て昭和42年10月31日, 日本ゴム協会関東支部月例会に打 いて発表した。 その際慈切なるご批評とご鞭撻を賜った 樋口桜五, 金子秀男, 北島採一, 占部䙘亮の諸先生に厚 く枋礼用し上げます。

また赤外，紫外分析の解析についてご助力を打願いし た出光嬹産川崎詿験室の方々にあわせて㧍礼申し上げま 于.

\section{文献}

1) 棚谷篤志郎：日ゴム協誌，43，212(1970)

2）棚谷篤志郎：日ゴム協誌，43，217 (1970)

3) 中西香爾：実駚化学講座 1-I-上（1957）丸善

4) B. T. Brooks: The Chemistry of Petroleum
Hydrocarbon (1954) Reinhold Publishing CO. (N.Y)

5) R. G. J. Miller: Infrared Structural Correlation Tables (1967) Heyden \& Son LTD. (LONDON)

6) 名取信策訳：赤外吸収スペクトル入門 (1960) 東京化学同人

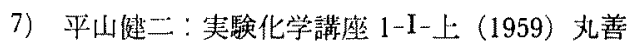

8) E. M. Charlet: Anal. Chem., 26, 861 (1954)

9) 雨容登三：石油化学（1959）産業図畫

10) 片山寛：油化学 5, 261 (1956)

11) J. P. Luonge : J. Polymer Sci., 57, 139 (1960)

12) 電気学会編：高分子材料の少化 (1958) コ口十

13) 原田一誠：実験化学諯座 続10（1965） 丸善

14）小泉正夫 : 光化学概諭（1963）朝倉

15）植村环：分光分析（1955）丸善

\section{STUDIES ON PHOTO-DISCOLORING PROCESSING OIL COMPONDED IN RUBBER (PART III )}

\section{CHEMICAL COMPOSITION AND PHOTO-STAINING MECHANISM OF PHOTO- STAINING SUBSTANCES CONTAINED IN RUBBER PROCESSING OIL}

\section{T. Tanaya (Technical Service Division, Shiraishi Kogyo Kaisha Ltd.)}

In the preceding report, the author reported separation of fractions $A_{2}$ and $R_{1}$ having photo-staining property and strong fluorescence from light colored rubber processing oil, applying elution chromatography. Of these fractions, the author obtained IR and UV absorption spectra and examined their composition.

The author observed that the fractions $A_{2}$ and $R_{1}$ comprise a variety of polycyclic aromatic hydrocarbons possessing alkyl side chain, as well as anthracene, phenanthrene, pentacene, etc. It was also found that certain amounts of $\mathrm{S}$, and $\mathrm{N}$, etc. too are included in their composition.

After discoloring these fractions $A_{2}$ and $R_{1}$ by irradiation of light, their IR and UV absorption spectra were analyzed and as a result, a wide range of : $\mathrm{C}=\mathrm{O}$ absorption was observed in $1700 \sim 1800-\mathrm{cm}$ band, with per oxide, ketone, aldehyde, alcohol, carboxylic acid, etc. being found to be formed. Apart from this, the author tried irradiation of the fractions $A_{2}$ and $R_{1}$ in $N_{2}$ gas, but observed no photo-staining at all.

Summing up these facts, the photo-staining phenomenon of light colored processing oil compounded rubber goods in presumed to be a phenomenon of oxidation of polycyclic aromatic hydrocarbons existing in oil being caused by irradiation of light in the existence of oxygen. 